\title{
Long-term effects and complication rates of Coonrad-Morrey total elbow arthroplasty - a retrospective analysis of 95 prostheses in 16-year follow-up
}

\begin{abstract}
Objectives: To investigate long-term effects and complication rates after Coonrad-Morrey semi-constrained total elbow replacement.
\end{abstract}

Methods: Retrospective analysis of consecutive Coonrad-Morrey total elbow arthroplasties performed in 1995-2006.

Results: The mean Mayo elbow score was 47.0 (SD 21.9) points preoperatively and 87.0 (SD 13.7) at the end of 16-year follow-up $(\mathrm{p}<0.001)$. The respective figures for mean pain in motion were 6.1 (SD 2.8) and 0.7 (SD 1.9) points $(\mathrm{p}<0.001)$. At the end of follow-up, the average extension lag was $30^{\circ}$, flexion $135^{\circ}$, pronation $67^{\circ}$, and supination was $74^{\circ}$. The complication rate was $19 \%$.

Conclusion: Semi-constrained linked Coonrad-Morrey total elbow arthroplasty displayed promising clinical results and a long-lasting satisfaction in the surgery results. In the 16year follow-up, there were 12 periprosthetic fractures and the overall complication rate was $19 \%$.

Keywords: Semi-constrained elbow arthroplasty, Coonrad- Morrey total elbow arthroplasty, Elbow Arthroplasty, Rheumatoid Arthritis and elbow arthroplasty
Volume II Issue 2 - 2019

\author{
Miika Stenholm,' Hannu Tiusanen,' Pjotr \\ Sarantzin,' Timo Lindström, ${ }^{2}$ Mikhail \\ Saltychev ${ }^{3}$ \\ 'Tyks Orto, Department of rheumaorthopaedics, Turku \\ University Hospital, Finland \\ ${ }^{2}$ Hospital Mehiläinen, Finland \\ ${ }^{3}$ Department of Physical and Rehabilitation Medicine, Turku \\ University Hospital and University of Turku, Finland
}

Correspondence: Hannu Tiusanen, Tyks Orto, Department of rheumaorthopaedics, Turku University Hospital,Turku, Finland, Email hannu.tiusanen@tyks.fi

Received: February 26, 2019 | Published: March 01, 2019

\section{Introduction}

The first total elbow arthroplasty of constrained type was installed by Dee in $1972 .{ }^{1}$ Even though he had reported good clinical results, the component loosening had been common. In 1982, Morrey and Bryan have also reported up to $27 \%$ rate of component loosening of that early type of constrained prostheses in a five-year follow-up. ${ }^{2}$ Strong forces at the bone cement interface of hinged prosthesis has been suggested as a reason for that loosening. Thus, that kinds of constrained prostheses have been retired from a practice.

The original Coonrad type-I total elbow prosthesis (Zimmer Biomet, Warsaw, Indiana, USA) has been introduced in 1973. This prosthesis has had high-molecular-weight polyethylene bushings with only $2^{\circ}$ to $3^{\circ}$ of laxity in a joint. In 1978 , the prosthetic design has been modified (Coonrad type-II) to increase varus/valgus laxity up to $7^{\circ}$ reducing the incidence of aseptic loosening. ${ }^{3-5}$ In 1981, the addition of anterior flange with bone graft and components' porous coating (Coonrad-Morrey type-III) has further decreased the incidence of prosthetic loosening. ${ }^{6}$ In 1982, Coonrad has presented the results of seven-year follow-up after type-I and type-II prosthetic surgery. ${ }^{4}$ Later, Morrey et al., ${ }^{2}$ King et al., ${ }^{7}$ and Lee et al. ${ }^{8}$ have presented the respective results of Coonrad-Morrey type-III surgery. Only few reports have introduced the results of semi-constrained elbow arthroplasties in over 10-year follow-ups..$^{3-9}$ These studies have reported relatively high complication rates and emphasized the role of wear of polyethylene bushings and correction of soft tissue balance in achieving good long-lasting results. Further research on the subject has been indicated. The objective was to investigate long-term effects and complication rates after a Coonrad-Morrey semi-constrained total elbow replacement.

\section{Materials and methods}

This was a retrospective study on data obtained from the electronic patient records of all consecutive patients undergoing elbow joint replacement using a Coonrad-Morrey prosthesis in a university hospital between 1995 and 2006. All the patients had radiographic signs either of severe rheumatoid arthritis or secondary posttraumatic osteoarthritis associated with severe refractory pain and decreased elbow joint function. The university ethical committee has approved the study.

Plain radiographs were obtained for all the patients preoperatively and postoperatively and the severity of preoperative arthritic changes was graded from grade 1 to grade 5 as suggested by Larsen et al. ${ }^{10}$ The overall satisfaction in surgery results was categorized as follows: 4 - 'very satisfied', 3 - 'satisfied', 2 - 'no change', and 1 - 'worse'. Pain severity in motion and at rest was assessed using a numeric rating scale from 0 - 'no pain' to 10 - 'extreme pain'. ${ }^{11}$ Overall discomfort in an affected elbow was rated from 1 - 'least' to 4 - 'worst'. Active elbow range of motion (ROM) was assessed before the surgery and 36 (up to 252) months later by a physiotherapist using a manual goniometer with 5-degree precision. To categorize the radiolucency observed in X-ray images, humerus and ulna areas were divided in four zones (Figure 1). 

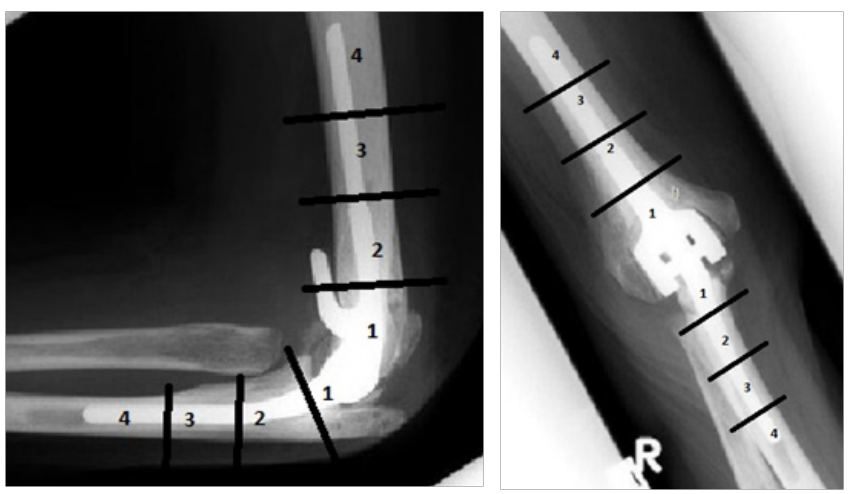

Figure I Radiologic zones used in the study.

\section{Statistical methods}

The results were reported as means, standard deviations, ranges, and percentage when appropriate. The paired sample t-test was used to analyze the differences between pre- and postoperative estimates with a 2 -tailed $p=<0.05$ considered statistically significant. All the statistical analyses were carried out using IBM SPSS Statistics for Windows, Version 21.0, IBM Corp. Released 2012, Armonk, NY: IBM Corp.

\section{Results}

Of the 95 patients (mean age 67 [SD 13.1] years, 88 [93\%] women), $80(84 \%)$ had rheumatoid arthritis and $15(16 \%)$ posttraumatic osteoarthritis as a reason for the surgery. Right elbow was operated in $47(49 \%)$ cases. Preoperatively, the Larsen score was on average 4.3 (SD 0.6) points and mean Mayo elbow score was 47.0 (SD 21.9) points (Table 1). The satisfaction in surgery was on average 3.6 (SD $0.7)$ points.

\section{$\mathrm{X}$-ray imaging during follow-up}

Of the patients, $21(22 \%)$ had radiolucent lines in ulnar zone $1,11(12 \%)$ in ulnar zone 2 , seven $(7 \%)$ in ulnar zone 3 , and nine patients $(10 \%)$ had radiolucent lines in ulnar zone 4 . Respectively, $22(23 \%)$ patients had radiolucent lines in humeral zone 1, $11(12 \%)$ humeral zone 2 , four (4\%) humeral zone 3 , and four (4\%) patients had radiolucent lines in humeral zone 4 .

\section{Complication rates}

Complications were seen in 18 patients $(19 \%)$. Three patients got infections (skin fistulas) - one treated conservatively, another by fistulae excision, and the third one by a two-stage revision. There were 12 periprosthetic fractures. Of them, one appeared after falling between the ends of shoulder and elbow prosthesis - due to severe osteoporosis the fracture was treated with a plate and a strut graft. Another patient had periprosthetic shaft fracture and was treated by plating. Three patients had a fracture of the medial condyle and were treated conservatively. Four patients had avulsion of the olecranon process. One patient had a fracture of both condyles and was treated conservatively. One patient had stress fracture on the ulnar side and was treated conservatively. One patient had periprosthetic fracture on the ulnar side and, after the initial plating, needed the replacement of ulnar component to a longer one, bone grafts, and plating with strut graft. Two patients had loosening of the hinge system. Of them, one was treated conservatively while another needed a hinge replacement. One patient reported the numbness of ulnar nerve. Time to revision is presented in Table 2.
Table I Sample characteristics and main results

\begin{tabular}{|c|c|c|c|c|}
\hline Variable & $\mathbf{n}$ & $\%$ & & \\
\hline \multicolumn{5}{|l|}{ Gender } \\
\hline Men & 7 & $7 \%$ & & \\
\hline Women & 88 & $93 \%$ & & \\
\hline \multicolumn{5}{|l|}{ Main diagnosis } \\
\hline Rheumatoid arthritis & 80 & $84 \%$ & & \\
\hline $\begin{array}{l}\text { Posttraumatic } \\
\text { osteoarthritis }\end{array}$ & 16 & $16 \%$ & & \\
\hline \multirow[t]{2}{*}{ Operation side, right } & 47 & $40 \%$ & & \\
\hline & Mean & Range & $\begin{array}{l}\text { Standard } \\
\text { deviation }\end{array}$ & $p$-value \\
\hline $\begin{array}{l}\text { Age at the time of } \\
\text { surgery, years }\end{array}$ & 67.0 & 41 to 99 & 13.1 & \\
\hline Larsen preop & 4.3 & 2 to 5 & 0.6 & \\
\hline Mayo score & & & & $<0.001$ \\
\hline Baseline & 47 & 0 to 95 & 21.9 & \\
\hline Follow-up & 87 & 40 to 100 & 13.7 & \\
\hline $\begin{array}{l}\text { Discomfort at } \\
\text { baseline }\end{array}$ & 3.5 & 0 to 4 & 0.7 & \\
\hline Pain at rest & & & & $<0.001$ \\
\hline Baseline & 3.8 & 0 to 10 & 3.3 & \\
\hline Follow-up & 0.4 & 0 to 8 & 1.3 & \\
\hline Pain in motion & & & & $<0.001$ \\
\hline Baseline & 6.1 & 0 to 10 & 2.8 & \\
\hline Follow-up & 0.7 & 0 to 8 & 1.9 & \\
\hline \multicolumn{5}{|l|}{ Range of motion } \\
\hline Extension lag & & & & 0.98 \\
\hline Baseline & 30 & 0 to 85 & 19.2 & \\
\hline Follow-up & 30 & 0 to 85 & 16.4 & \\
\hline Flexion & & & & $<0.001$ \\
\hline Baseline & 120 & 0 to 150 & 27.9 & \\
\hline Follow-up & 135 & 100 to 150 & 10.8 & \\
\hline Pronation & & & & $<0.001$ \\
\hline Baseline & 54 & 0 to 90 & 25.9 & \\
\hline Follow-up & 67 & 15 to 90 & 17.9 & \\
\hline Supination & & & & $<0.001$ \\
\hline Baseline & 69.8 & 0 to 100 & 23.3 & \\
\hline Follow-up & 74 & 0 to 105 & 84.0 & \\
\hline
\end{tabular}


Table 2 Time to revision surgery $(n=8)$

\begin{tabular}{ll}
\hline Elbow & Years \\
\hline 1 & 0.3 \\
2 & 0.8 \\
3 & 1.4 \\
4 & 5 \\
5 & 6 \\
6 & 9 \\
7 & 11 \\
8 & 15 \\
\hline
\end{tabular}

\section{Discussion}

In this retrospective study of 95 patients with Coonrad-Morrey prostheses, pain level as well as elbow function and range of motion were good at the end of 16-year follow-up. The overall complication rate was 19\%. Radiolucent lines were seen in zones 3 and 4 (Figure 1) of both components indicating loose implants. Eight patients needed a revision surgery - a change of one or more prosthetic components. There were 12 periprosthetic fractures. Most of the fractures in condyle or olecranon process were treated conservatively. Three patients had deep infection but only one needed a two-stage revision. The generalisability of the results might be affected by the fact that this was a retrospective uncontrolled study amongst patients of a single university clinic. The sample was predominated by women. During the follow-up, medication or other treatments were not comprehensively recorded. The surgery records did not contain a comprehensive description of cementing technique, used cement, or plugs used in the operation. On the other hand, this study employed the rare opportunity to observe the survival timeline of Coonrad-Morrey arthroplasty for over 15 years using a reliable source of information electronic patient records created in a university clinic.

There have only been a few publications on the long-term effects of Coonrad-Morrey arthroplasty. In a 11-year follow-up study, Gill and Morrey ${ }^{9}$ have placed a survival rate of prostheses at $92 \%$ and reported good results regarding elbow function, pain level, range of motion, and general satisfaction with the surgery. They have observed loosening of the humeral and ulnar stems and partial $(13 \%)$ or severe $(7 \%)$ wear of polyethylene bushings. In that study, the overall complication rate has been reported as $14 \%$ requiring surgical revision in $13 \%$ with the most common complications being triceps muscle's avulsion, deep infection, ulnar fracture, and ulnar stem fracture. In another study by Aldridge et al., the average survival rate has been set at 18 years and complication rate at $32 \%$ requiring revision in $14 \%$ and polyethylene bushings' changing in $12 \%{ }^{6}$

It appears that the most common problem with this implant type is wear of polyethylene bushings at the hinge. ${ }^{8,13}$ There seems to be a relationship between wear and preoperative elbow deformity that is not corrected by soft tissue balancing during the procedure. ${ }^{8,14}$ Younger age, intensive postoperative physical activity, and faulty implant positioning also seem to contribute to that wear. ${ }^{8,12,13}$ It has been suggested that rotational issues between humeral and ulnar stems may lead to an excessive load on the hinge mechanism. ${ }^{15}$ In a 4-year follow-up, Hildebrand et al. ${ }^{16}$ have observed increased (rate 32\%) osteolysis around ulnar stems comparing to humeral stems. ${ }^{17}$ The appearance of osteolysis has been associated with the type of coating used in ulnar stem and has been more frequent in posttraumatic osteoarthritis comparing to rheumatoid arthritis.

The complication rate observed in this study was close to those reported previously. In this study, 12 periprosthetic fractures were observed. The $51 \%$ of patients had some kind of radiolucent lines around the ulnar component and $43 \%$ of patients had that around the humeral component indicating an aseptic loosening as a plausible reason for periprosthetic fractures. Aseptic loosening may depend on a used cementing technique, cement, and plugs. Further research on conducted larger samples, using prospective designs, and in different settings is needed. Such research might focus on comparison between different types of components, operation and cementing techniques to lessen the high rate of periprosthetic fractures and complication rate in semi constrained elbow arthroplasty. Better understanding of elbow biomechanics and better implant designs will make the results better.

\section{Conclusion}

Semi-constrained linked Coonrad-Morrey total elbow arthroplasty displayed promising clinical results and a long-lasting satisfaction in the surgery. In the 16-year follow-up, there were 12 periprosthetic fractures and the overall complication rate was $19 \%$.

\section{Conflicts of interest}

None to declare except.

Hannu Tiusanen: A Consultant fee from Zimmer Biomet.

\section{Acknowledgments}

None to declare.

\section{References}

1. Dee R. Total replacement of the elbow joint. Orthop Clin North Am. 1973;4(2):415-433.

2. Morrey BF, Bryan RS. Complications of total elbow arthroplasty. Clin Othop. 1982;170:204-212.

3. Coonrad RW. History of total elbow arthroplasty. In: Inglis AE, ed. Symposium on total joint replacement of the upper extremity 1979. St Louis: C.V. Mosby Co. 1982;75-90.

4. Coonrad RW. Seven year follow-up of Coonrad total elbow replacement. In: Inglis AE, ed. Symposium on total joint replacement of the upper extremity, 1979. St. Louis: C.V. Mosby Co. 1982;91-99.

5. Cooney WP. Elbow arthroplasty: historical perspective and current concepts. In: Morrey BF, ed. The elbow and its disorders. Third ed. Philadelphia: W.B. Saunders Co. 2001;583-601.

6. Morrey BF, Adams RA. Semi constrained arthroplasty for the treatment of rheumatoid arthritis of the elbow. J Bone Joint Surg Am. 1992; 74(4):479-490.

7. King GC, Adams RA, Morrey BF. Total elbow arthroplasty: revision with use of a non-custom semi-constrained prosthesis. J Bone Joint Surg Am. 1997;79(3):394-400.

8. Lee BP, Adams RA, Morrey BF. Polyethylene wear after total elbow arthroplasty. J Bone Joint Surg Am. 2005;87(5):1080-1087.

9. Gill DR, Morrey BF. The Coonrad-Morrey total elbow arthroplasty in patients who have rheumatoid arthritis: a ten to fifteen-year follow-up study. J Bone Joint Surg Am. 1998;80(9):1327-1325.

10. Larsen A, Dale K, Eek M. Radiographic evaluation of rheumatoid arthritis and related conditions by standard reference films. Acta Radiol Diagn (Stockh). 1977;18(4):481-491. 
11. D Gould. Visual Analogue Scale (VAS). Journal of Clinical Nursing. 2001;10:697-706.

12. Aldridge JM, Lightdale NR, Mallon WJ, et al. Total elbow arthroplasty with the Coonrad/Coonrad-Morrey prosthesis- sis. A 10- to 31-year survival analysis. J Bone Joint Surg Br. 2006;88(4):509-514.

13. Goldberg SH, Urban RM, Jacobs JJ, et al. Modes of wear after semi-constrained total elbow arthroplasty. J Bone Joint Surg Am. 2008;90(3):609-619.

14. Schneeberger AG, Adams R, Morrey BF. Semiconstrained total elbow replacement for the treatment of post-traumatic osteoarthrosis. $J$ Bone Joint Surg Am. 1997;79(8):1211-1222.
15. Celli A, Morrey BF. Total elbow arthroplasty in patients forty years of age or less. J Bone Joint Surg Am. 2009;91(6):1414-1418.

16. Hildebrand KA, Patterson SD, Regan WD, et al. Functional outcome of semi-constrained total elbow arthroplasty. J Bone Joint Surg Am. 2000;82(10):1379-1386.

17. Schuind F, O'Driscoll S, Korinek S, et al. Loose- hinge total elbow arthroplasty. An experimental study of the effects of implant alignment on three dimensional elbow kine- matics. J Arthroplasty. 1995;10(5):670678 . 